DOI 10.37882/2223-2974.2021.01.09

\title{
СОВРЕМЕННЫЕ КОНЦЕПЦИИ УПРАВЛЕНИЯ ИННОВАЦИОННЫМ РАЗВИТИЕМ ЧЕЛОВЕЧЕСКОГО КАПИТАЛА
}

\section{MODERN CONCEPTS OF MANAGEMENT OF INNOVATIVE DEVELOPMENT OF HUMAN CAPITAL}

\section{R. Evloev}

Summary: Relevance. The relevance of scientific research is due to the rapid stage of development of an innovative economy, one of the constituent components of which is human capital.

In order to ensure the effective implementation of digitalization activities and the development of an innovative economy in the territory of the Russian Federation, we need related resources, including human capital, the strategy of innovative development of which is an urgent issue for our state.

The purpose of the study is to conduct a research analysis of the features of the main modern concepts used in the management of innovative development of human capital.

Research objectives. The article discusses the need to form a model of an innovative economy. The characteristics of the strategy of innovative development of human capital are described. Listed are the transformation processes observed in the development of an innovative economy and taking into account its impact on the labor market. The features of the main modern concepts of managing the innovative development of human capital, which are used in domestic and foreign practice, are considered. A model aimed at managing the innovative development of human capital in the context of modern economic transformation is proposed.

Research results. The main modern concepts of managing the innovative development of human capital are the concept of satisfying the needs of the enterprise, the concept of finding solutions aimed at foresight, the concept of forming teams of oriented specialists and employees, the concept of forming new personnel competencies and the concept of personnel training management. At the same time, we can propose the following model for managing the innovative development of human capital, which is formed from education, the formation of readiness for self-development, digital literacy, the formation of intellectual capital, the creation of skills for the integrated use of knowledge and the formation of competitive conditions in the labor market.

Keywords: innovative development; human capital; labor resources; human resources; innovative economy; innovative activity; digital transformation; labor productivity; quality of human resources.

\author{
Евлоев Руслан Гириханович \\ Аспирант, Московский финансово-промышленный \\ университет «Синергия», Москва \\ Sflen2007@mail.ru
}

Аннотация: Актуальность. Актуальность научного исследования обусловлена стремительным этапом развития инновационной экономики, одним из составляющих компонентов которой выступает человеческий капитал.

С целью обеспечения эффективного проведения мероприятий по цифровизации и развитию инновационной экономики на территории Российской Федерации, необходимы сопутствующие ресурсы, среди которых человеческий капитал, стратегия инновационного развития которого - актуальный вопрос для нашего государства.

Цель исследования заключается в проведении исследовательского анализа особенностей основных современных концепций, используемых при управлении инновационным развитием человеческого капитала.

Задачи исследования. В рамках статьи рассмотрена необходимость формирования модели инновационной экономики. Описана характеристика стратегии инновационного развития человеческого капитала. Перечислены трансформационные процессы, наблюдаемые в рамках развития инновационной экономики и с учетом ее влияния на рынок труда. Рассмотрены особенности основных современных концепций управления инновационным развитием человеческого капитала, которые используются в отечественной и зарубежной практике. Предложена модель, направленная на управление инновационным развитием человеческого капитала в условиях современной трансформации экономики.

Результаты исследования. Основными современными концепциями управления инновационным развитием человеческого капитала выступают концепция удовлетворенности потребностей предприятия, концепция поиска решений, направленных на предвидение, концепция формирования команд ориентированных специалистов и сотрудников, концепция формирования новых компетенций персонала и концепция управления обучением персонала. При этом, можно предложить следующую модель управления инновационным развитием человеческого капитала, формирующуюся из получения образования, формирования готовности к саморазвитию, получения цифровой грамотности, формирования интеллектуального капитала, создания умений комплексного использования знаний и формирование условий конкурентоспособности на рынке труда.

Ключевые слова: инновационное развитие, человеческий капитал, трудовые ресурсы, человеческие ресурсы, инновационная экономика, инновационная деятельность, цифровая трансформация, производительность труда, качество человеческих ресурсов.
$\mathrm{H}$ а сегодняшний день формирование инновационной экономики России характеризуется применением различных цифровых технологий и инноваций, связанных с процессами цифровой трансформации финансово-производственной деятельности предпри- ятий.

С целью обеспечения эффективного проведения данных мероприятий, необходимы сопутствующие ресурсы, среди которых человеческий капитал, стратегия иннова- 
ционного развития которого - актуальный вопрос для нашего государства.

В частности, в связи с этим происходит активный процесс формирования различных современных концепций управления инновационным развитием человеческого капитала, направленных на обеспечение роста качества трудовых ресурсов и эффективности их использования в производственных целях (что отражается через основной индикатор - уровень производительности труда).

Актуальность научного исследования на тематику «современные концепции управления инновационным развитием человеческого капитала» обусловлена стремительным этапом развития инновационной экономики, одним из составляющих компонентов которой выступает человеческий капитал.

По этой причине, целью научной статьи выступает исследовательский анализ особенностей основных современных концепций, используемых при управлении инновационным развитием человеческого капитала.

Для этого, в рамках научного исследования, необходимо решение следующих актуальных задач, среди которых:

- рассмотреть необходимость формирования модели инновационной экономики;

- описать характеристики стратегии инновационного развития человеческого капитала;

- перечислить трансформационные процессы, наблюдаемые в рамках развития инновационной экономики и с учетом ее влияния на рынок труда;

- рассмотреть особенности основных современных концепций управления инновационным развитием человеческого капитала, которые используются в отечественной и зарубежной практике;

- предложить модель, направленную на управление инновационным развитием человеческого капитала в условиях современной трансформации экономики.

Развитие инновационной экономики в России и других странах мира имеет важное значение и практическую роль при социально-экономическом развитии государства. В случае торможения трансформационных процессов формирования национальной инновационной системы и цифровизации бизнеса/производства возможны негативные последствия, как:

- потеря конкурентоспособности страны;

- снижение уровня инвестиционной привлекательности;

- ухудшение макроэкономической статистики;

- рост уровня государственного долга;

- проявление признаков бюджетного, финансового и валютного кризиса.
Поскольку человеческий капитал в рамках развития инновационной экономики занимает одно из главных составляющих, характеристика такой стратегии будут выступать [1]:

- высокий уровень развития системы профессионального обучения и образования молодежи;

- тесная взаимосвязь между сферой научно-исследовательской деятельности и производством товаров и услуг;

- наличие субъектов и элементов национальной инновационной системы и инфраструктуры, способствующих инновационному развитию человеческого капитала.

Процесс инновационного развития человеческого капитала характеризуется тем, что все большее число людей заняты в сферах, связанных с применением инновационных технологий, сектора услуг, а не сельского хозяйства или промышленного производства (см. рисуHOK 1).

Инновационное развитие российской экономики позволяет формировать следующие трансформационные процессы, наблюдаемые на отечественном рынке трудовых ресурсов, среди которых [5]:

- неформальная занятость;

- виртуальная занятость;

- неполная занятость;

- самозанятость;

- временная занятость.

Также, происходят следующие процессы при инновационном развитии человеческого капитала, как:

1. Увеличивается потребность к сотрудникам понимать и уметь пользоваться цифровыми сервисами и информационными технологиями.

2. Все чаще подбор и отбор персонала происходит с помощью технологий машинного обучения.

3. Аспекты профессионального обучения и трудовой переориентации происходит с помощью технологий виртуальной реальности.

4. Формируются новые компании, особенностью которых является создание проектной команды на отдельный бизнес-проект, после реализации которых идет переключение на другие проектные группы и задачи.

5. Возрастает число сотрудников, работающих в режиме удаленной занятости.

Благодаря фундаментальному подходу к управлению инновационным развитием человеческого капитала можно прийти к выводу о влиянии комплекса применяемых практик управления трудовыми ресурсами на повышение эффективности коммерческой деятельности хозяйствующих субъектов в экономике страны [2]. 


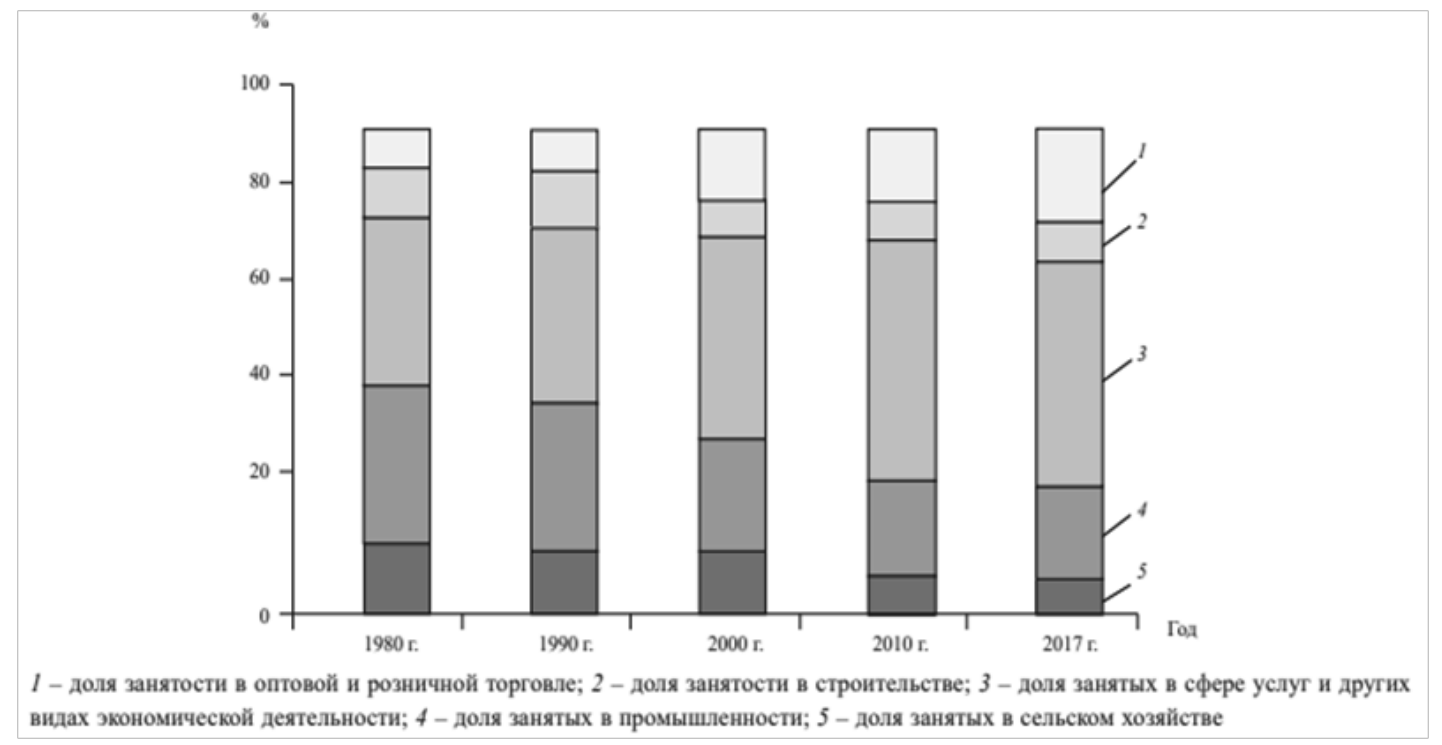

Рис. 1. Структура занятости по отраслям экономической деятельности [8].

Благодаря стратегическому подходу к управлению инновационным развитием человеческого капитала можно прийти к выводу о том, что перспективы управления трудовыми ресурсами позволяют формировать основу под создание новых объектов производства, отраслей, базовых секторов экономики страны и рынков потребительских товаров и услуг [2].

По мнению Золин И.Е., «формирование модели инновационной экономики в Российской Федерации повлечет за собой очень много изменений во всех отраслях. Потребуются другие знания, другие специалисты. Эта перестройка, ломка, естественно, заденет многих. В связи с этим, отдельный спрос на работников низкой квалификации будет неизбежно снижаться, а высококлассный специалист, который имеет хорошее образование, в инновационной модели экономики будет наиболее востребован» [6].

Согласно мнению Алексеева Н.В. и Сазонова А.А., у России есть потенциал в использовании человеческого капитала для борьбы за лидирующие технологические позиции при формировании мировой инновационной модели экономики, где цифровые технологии и интеллектуальные ресурсы - основные инструменты управления конкурентоспособностью производства и продукции [4].

И чтобы данная процедура была реалистичной, важно выбрать правильны векторы управления инновационным развитием человеческого капитала, зависящих от современных концепций.

Перейдем к исследованию особенностей основных современных концепций управления инновационным развитием человеческого капитала, которые использу- ются в отечественной и зарубежной практике [3].

1. Концепция удовлетворенности потребностей предприятия. Особенности применения данной концепции управления инновационным развитием человеческого капитала характеризуют следующее:

- трудовые ресурсы и их формирование должны включать не текущие потребности предприятий в специальностях и профессиях, а новосозданные направления хозяйственной деятельности;

- большего спроса на новые профессии со стороны предприятий пока что нет, однако это измениться в ближайший период;

- потребность в новых профессиях и специальностях будет пропорционально расти с увеличением финансовых инвестиций в создание интеллектуального капитала предприятий.

2. Концепция поиска решений, направленных на предвидение. Особенности применения данной концепции управления инновационным развитием человеческого капитала характеризуют следующее:

- развитие человеческого капитала направленно на формирование креативного мышления у людей;

- формируется творческий подход к решению проблем;

- принятие решений усложняется из-за увеличения количества альтернативных вариантов.

3. Концепция формирования команд ориентированных специалистов и сотрудников. Особенности применения данной концепции управления инновационным развитием человеческого капитала характеризуют следующее:

- главным стилем управления организационной 
структурой предприятия является сетевой подход;

- ключевым инструментом принятия управленческих решений является коллективное обсуждение;

- накопление знаний и навыков у одного сотрудника позволяет передавать их других партнерам по рабочей команде.

4. Концепция формирования новых компетенций персонала. Особенности применения данной концепции управления инновационным развитием человеческого капитала будут рассмотрены далее, поскольку следующая концепция управления инновационным развитием человеческого капитала взаимосвязана с этой.

5. Концепция управления обучением персонала. Особенности применения данной концепции управления инновационным развитием человеческого капитала характеризуют следующее:

- традиционный подход к управлению человеческим капиталом, основанный на принципах рационального обучения больше не отвечает адекватным образом на запросы времени и рынка труда;

- возрастает роль вузовского и послевузовского обучения, но они уступают профессиональному обучению, организованного предприятиями.

Развитие системы высшего образования, которая будет соответствовать потребностям инновационной модели развития экономики с потребует решение ряда внутренних кадровых и организационных проблем российских вузов [7].

Согласно последней концепции управления инновационным развитием человеческого капитала, в ситуации, когда личных навыков участников и лидера команды недостаточно для успешной деятельности, логично прибегнуть к помощи внешних инструментов, таких как различные тренинги.

Исходя из этого, можно предложить следующую модель, направленную на управление инновационным развитием человеческого капитала в условиях современной трансформации экономики [9; 10]:

- получение профессионального высшего образования в соответствии с выбранным направлением специальности;

- формирование готовности к саморазвитию человека через создание его профессиональных компетенций;

- получение образования цифровой грамотности;

- формирование интеллектуального капитала в рамках человеческого ресурса;

- создание умения применять знаний, навыки и информацию комплексно, а не по отдельности;

- формирование условий конкурентоспособности специалиста на рынке труда.

Таким образом, подводя итоги научного исследования, можно прийти к следующему заключению, что основными современными концепциями управления инновационным развитием человеческого капитала выступают концепция удовлетворенности потребностей предприятия, концепция поиска решений, направленных на предвидение, концепция формирования команд ориентированных специалистов и сотрудников, концепция формирования новых компетенций персонала и концепция управления обучением персонала.

При этом, можно предложить следующую модель управления инновационным развитием человеческого капитала, формирующуюся из получения образования, формирования готовности к саморазвитию, получения цифровой грамотности, формирования интеллектуального капитала, создания умений комплексного использования знаний и формирование условий конкурентоспособности на рынке труда.

\section{ЛИТЕРАТУРА}

1. Черноталова Е.В. Развитие человеческого капитала в условиях инновационной экономики // Вестник КрасГАУ. 2014. №4.

2. Елена В.Ш. Трансформация концепции управления человеческим капиталом в зависимости от этапов развития промышленности // Вопросы управления. 2019. №2 (38).

3. Ширинкина Е.В. Управление человеческим капиталом в парадигме цифрофизации: проблемы и принципы управления // Вопросы управления. 2018. №6 (36).

4. Алексеева Н.В., Сазонов А.А. Анализ степени влияния цифровой экономики на формирование основных трендов на рынке труда и социально-трудовых отношений в Российской федерации // Вестник МГОУ. Серия: Экономика. 2019. №2.

5. Романюк И.Д. Модернизация форм занятости в современном мире // Известия СПбГЭУ. 2018. №6 (114).

6. Золин И.Е. Роль цифровой экономики в развитии системы непрерывного образования // Logos et Praxis. 2019. №1.

7. Ахапкин Н.Ю., Волкова Н.Н., Иванов А.Е. Развитие цифровой экономики и перспективы трансформации российского рынка труда // Вестник Института экономики РАН. 2018. №5.

8. Кауфман Н.Ю. Генезис конфликтов развития рынка труда в условиях цифровой экономики // Вестник ГУу. 2019. №5. 
9. Сизова И.Л., Хусяинов Т.М. Труд и занятость в цифровой экономике: проблемы российского рынка труда // Вестник Санкт-Петербургского университета. Социология. 2017. №4.

10. Ma, L., Zhai, X., Zhong, W., \& Zhang, Z. X. (2019). Deploying human capital for innovation: A study of multi-country manufacturing firms. International Journal of Production Economics, 208, 241-253.

11. Кондаков М.В. Современные тенденции и перспективы развития российского рынка труда // XI международный молодежный форум «0бразование. Наука. Производство». 2019. С. 2061-2066.

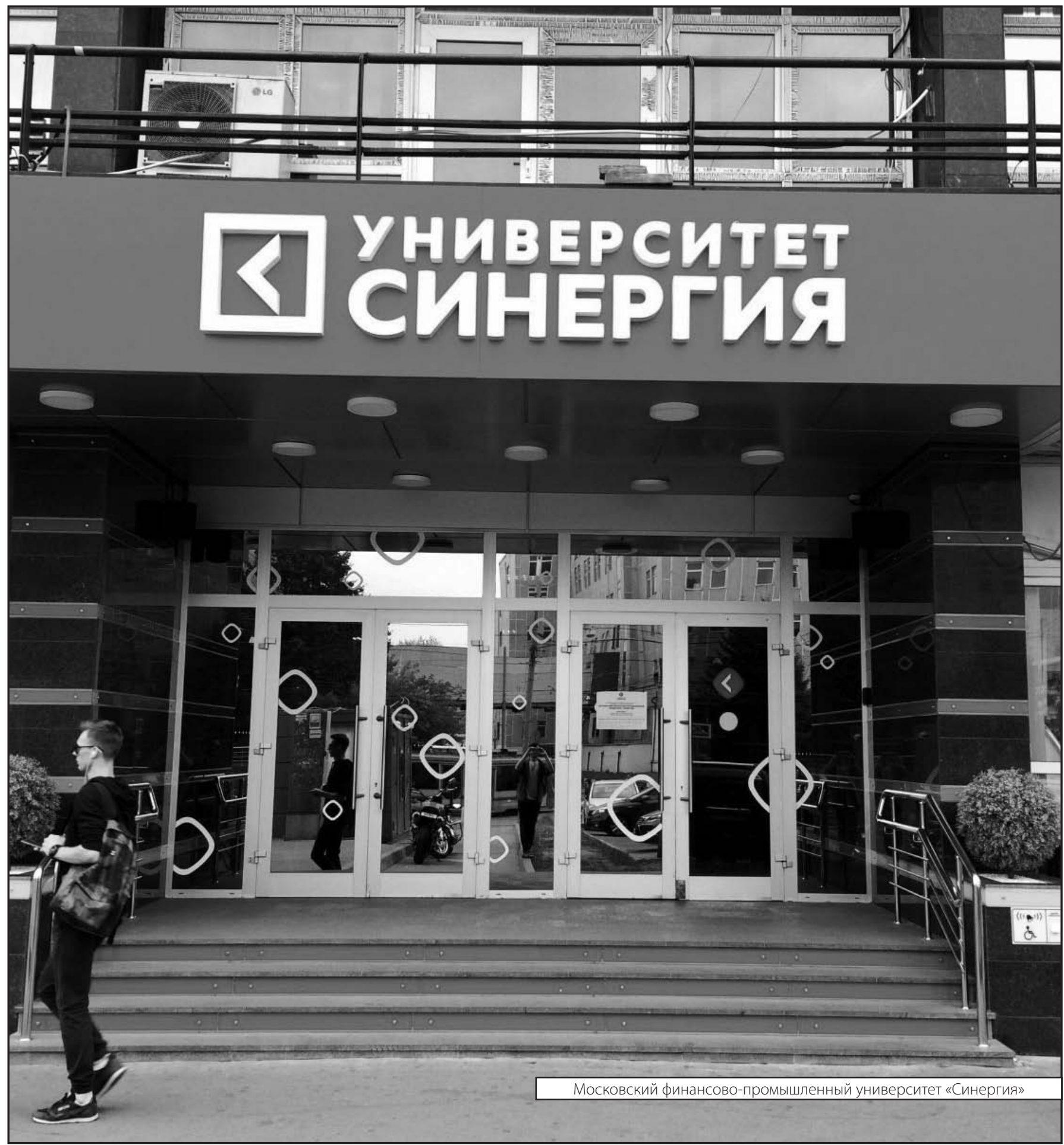

